\title{
Brief Review: Atrial Fibrillation in Hyperthyroidism Increases Propensity to Stroke
}

\author{
Inamullah Khan, ${ }^{1}$ Muhammad Salman Khan, ${ }^{2}$ and Farid Khan ${ }^{1,}$ \\ ${ }^{1}$ The Aga Khan University Medical College, Karachi. Pakistan 74800 \\ ${ }^{2}$ Department of Radiology, The Aga Khan University Hospital, Karachi. Pakistan 74800 \\ "Corresponding author: Farid Khan, B11, Pak Tameer Plaza, Gulshan-e-Iqbal, Block 14, Karachi, Pakistan 75300. Tel: +92-3213581733, E-mail: drfaridkhan@hotmail.com
}

Received 2017 February 19; Revised 2017 May 01; Accepted 2017 July 01.

\begin{abstract}
Context: Deregulations of the bodily systems increase the predisposition to cerebrovascular diseases (CVDs). Thyroid hormone deregulations lead to an observed increase in predisposing such patients to stroke.

Evidence Acquisition: Online literature search was conducted using PubMed, Google Scholar, and Cochrane as databases.

Results: Increase in thyroid hormone level affects the cardiovascular system by increasing the density of beta-adrenergic receptors on cardiomyocytes. The highest post diagnosis risk in hyperthyroidism has been reported for atrial fibrillation and arterial embolism, which increases the risk of ischemic and nonischemic stroke. Atrial fibrillation has thromboembolic stroke as one of the feared outcomes.

Conclusions: Preexisting literature has considerable evidence of increased risk of CVDs in patients with hyperthyroidism and atrial fibrillation together, compared with patients who have either of these diseases.
\end{abstract}

Keywords: Atrial Fibrillation, Hyperthyroidism, Stroke, Cerebrovascular

\section{Context}

Cerebrovascular diseases (CVDs) are caused by multiple factors and deregulations of bodily systems. Deregulation of endocrine system such as thyroid hormones abnormality has also been observed to predispose to stroke. Thyroid hormones disorders most commonly manifest in the form of hypo- or hyperthyroidism along with subclinical stages as detected by screening tests $(1,2)$. New hyperthyroid cases have been reported at a rate of $23-93 / 100,000$ per year in different countries across the globe (3). Thyroid hormones have substantial effects on the cardiovascular system, particularly by increasing the density of betaadrenergic receptors on the cardiomyocytes (4), which in turn can lead to atrial fibrillation (AF) occurring at a rate of 5\% to $15 \%$ in hyperthyroidism (5).

The highest post diagnosis risk in hyperthyroidism has been reported for atrial fibrillation and arterial embolism, which increases the risk of ischemic and nonischemic stroke by 2 to 3 folds (6). AF itself, in the absence of hyperthyroidism, is a strong indicator of future CVDs in patients if not monitored and managed properly.

In previous studies, stroke with determined etiology has been associated with syndromes such as moyamoya syndrome (7), antiphospholipid (8), dissection (9), systemic lupus erythematosus (10), coagulopathy, and migraine (11). Primary purpose of this short review is to find whether the existing literature has evidence of risk multi- plication for stroke among patients who have both hyperthyroidism and AF simultaneously.

\section{Evidence Acquisition}

We conducted literature search using PubMed, Google Scholar, and Cochrane as databases. A total of 28 articles were identified by the initial search, out of which 9 were selected for the review as found most relevant by abstract screening.

\section{Results}

Atrial fibrillation has thromboembolic stroke as one of the feared outcomes. Atrial fibrillation has been reported to lead to $25 \%$ of ischemic cardiovascular and $50 \%$ of cardioembolic incidences (12). Ischemic strokes are reported at 5-fold increased risk with 1.5-fold increased risk of fatal stroke in atrial fibrillation (13).

In 1981, the reported rate of thromboembolic events in hyperthyroidism was $40 \%$ (14). The same study showed $53 \%$ of the thromboembolic phenomena as cerebral emboli, which led to ischemic events. Suggestion of anticoagulation was made in such patients with atrial fibrillation. In Framingham study, stroke rate for idiopathic $\mathrm{AF}$ was 41.8/1000 person-years, which is 5.6 times that of nonatrial fibrillation strokes (15). In a prospective study, Siu et 
al. looked at newly diagnosed ischemic stroke patients in China. They observed ischemic stroke in 9.4\% of hyperthyroid patients with $\mathrm{AF}$ compared to $3.1 \%$ nonthyroid $\mathrm{AF}(\mathrm{P}=$ $.02)$ and $0.6 \%$ in hyperthyroid without $\mathrm{AF}(\mathrm{P}<.001)$. The occurrence of ischemic stroke was predicted by hyperthyroidism (HR: 3.5, $\mathrm{P}=.03$ ) and persistent $\mathrm{AF}$ (HR:13.0, 95\% CI: 2.88 to $58.80, \mathrm{P}<.01$ ), when analyzed by Cox regression (16).

Hyperthyroidism has been associated with blood hypercoagulability. Blood hypercoagulability increases the risk for ischemic events. Hwang et al identified the occurrence of thrombotic events in brain vasculature in patients with hyperthyroidism. They specifically reported cases on superior sagittal sinus thrombosis (17). In November 2014, Chaker et al. conducted a meta-analysis of multiple studies from 1984 -1998, and they found that subclinical hyperthyroidism increased the risk of stroke. One of the reviewed studies revealed a statistically significant adjusted hazard ratio (HR) of 3.39, while the overall pooled estimated HR of 1.17 (95\% CI 0.54 - 2.56) showed no association of subclinical hyperthyroidism (18).

In January 2014, Chen et al. looked into the level of Ddimer and ischemic events in 3 study groups: (1) Hyperthyroid AF, $n=62$; (2) Nonthyroid AF, $n=107$, and (3) Hyperthyroid without $A F, n=100$. The D-dimer levels were significantly higher in hyperthyroid with AF than in the other 2 groups. Over a period of 3 years, the follow- up showed higher incidence of ischemic stroke, when compared with nonthyroid AF (hazard ratio, HR: 3.2, 95\% confidence interval, CI: 1.01 - 5.59, P = 0.04) (19). Dekker et al. looked at allcause mortality in hyperthyroidism, which they found it to be the highest in the first 3 months postdiagnosis (HR:4.62, 95\% CI: 4.40 - 4.85), moreover, they reported an elevated mortality in the 3-year (long-term) follow-up (HR: 1.35, 95\% CI:1.33 - 1.37). The risk for all examined ischemic and nonischemic stroke was increased by $2-3$ folds in these patients (6).

Yang et al. used national health insurance research database of Taiwan to look for stroke in thyroid disorders. The results showed 38\% increased hazard of developing cerebrovascular insults in hyperthyroidism with HR of 1.38; hypothyroidism showed even a higher risk with HR of $1.89(20)$.

\section{Conclusions}

Preexisting literature has considerable evidence of increased risk of CVDs in patients with hyperthyroidism and atrial fibrillation together, compared with patients who have either of these diseases. Therefore, we encourage researchers to devise strategies to confirm this observation with more extensive and robust studies. This will not only help to make guidelines but it will also enable physicians and patients to apply timely preventative measures to minimize the augmented risk of stroke.

\section{Footnotes}

Funding/Support: It is stated that no funding was received in any form for completing this brief review.

Conflicts of Interest: The author declares no potential conflicts of interest with respect to the authorship or publication of this article.

\section{References}

1. Veltri F, Rocha FO, Willems D, Praet JP, Grabczan L, Kleynen P, et al. Prevalence of thyroid dysfunction and autoimmunity in the older population and implications of age-specific reference ranges. Clin Chim Acta. 2017;465:34-9. doi: 10.1016/j.cca.2016.12.008. [PubMed: 27988318].

2. Kelley S. Endocrinology Update: Thyroid Disorders. FP Essent. 2016;451:11-6. [PubMed: 27936530].

3. Abraham-Nordling M, Bystrom K, Torring O, Lantz M, Berg G, Calissendorff J, et al. Incidence of hyperthyroidism in Sweden. Eur J Endocrinol. 2011;165(6):899-905. doi: 10.1530/EJE-11-0548. [PubMed: 21908653].

4. Haro JM, Sabio JM, Vargas F. Renal beta-adrenoceptors in thyroxinetreated rats. J Endocrinol Invest. 1992;15(8):605-8. [PubMed:1331224].

5. Klein I, Ojamaa K. Thyroid hormone and the cardiovascular system. N Engl J Med. 2001;344(7):501-9. doi: 10.1056/NEJM200102153440707. [PubMed: 11172193].

6. Dekkers OM, Horvath-Puho E, Cannegieter SC, Vandenbroucke JP, Sorensen HT, Jorgensen JO. Acute cardiovascular events and all-cause mortality in patients with hyperthyroidism: a population-based cohort study. Eur J Endocrinol. 2017;176(1):1-9. doi: 10.1530/EJE-16-0576. [PubMed: 27697972].

7. Zipfel GJ, Fox DJ, Rivet DJ. Moyamoya disease in adults: the role of cerebral revascularization. Skull Base. 2005;15(1):27-41. doi:10.1055/s-2005868161. [PubMed: 16148982].

8. Panichpisal K, Rozner E, Levine SR. The management of stroke in antiphospholipid syndrome. Curr Rheumatol Rep. 2012;14(1):99-106. doi: 10.1007/s11926-011-0223-5. [PubMed: 22109663].

9. Schievink WI. Spontaneous dissection of the carotid and vertebral arteries. $N$ Engl J Med. 2001;344(12):898-906. doi: 10.1056/NEJM200103223441206. [PubMed: 11259724].

10. Kitagawa Y, Gotoh F, Koto A, Okayasu H. Stroke in systemic lupus erythematosus. Stroke. 1990;21(11):1533-9. [PubMed: 2237945].

11. Scher AI, Launer LJ. Migraine: migraine with aura increases the risk of stroke. Nat Rev Neurol. 2010;6(3):128-9. doi: 10.1038/nrneurol.2010.14. [PubMed: 20212428].

12. Gonzalez-Hermosillo JA, Márquez MF, Ocampo -S. Dise-o de un reg istro de fibrilacion auricular y riesgo embolico en Mexico: CARMENAF. Archivos de Cardiologia de Mexico; 2015.

13. Preuss R, Chenot JF, Angelow A. Quality of care in patients with atrial fibrillation in primary care: a cross-sectional study comparing clinical and claims data. Ger Med Sci. 2016;14:Doc13. doi: 10.3205/000240. [PubMed: 27980520].

14. Bar-Sela S, Ehrenfeld M, Eliakim M. Arterial embolism in thyrotoxicosis with atrial fibrillation. Arch Intern Med. 1981;141(9):1191-2. [PubMed: 7259379].

15. Wolf PA, Dawber TR, Thomas HJ, Kannel WB. Epidemiologic assessment of chronic atrial fibrillation and risk of stroke: the Framingham study. Neurology. 1978;28(10):973-7. [PubMed: 570666]. 
16. Siu CW, Pong V, Zhang X, Chan YH, Jim MH, Liu S, et al. Risk of ischemic stroke after new-onset atrial fibrillation in patients with hyperthyroidism. Heart Rhythm. 2009;6(2):169-73. doi: 10.1016/j.hrthm.2008.10.023. [PubMed: 19187905].

17. Hwang JU, Kwon KY, Hur JW, Lee JW, Lee HK. The role of hyperthyroidism as the predisposing factor for superior sagittal sinus thrombosis. J Cerebrovasc Endovasc Neurosurg. 2012;14(3):251-4. doi: 10.7461/jcen.2012.14.3.251. [PubMed: 23210057].

18. Chaker L, Baumgartner C, Ikram MA, Dehghan A, Medici M, Visser WE, et al. Subclinical thyroid dysfunction and the risk of stroke: a sys- tematic review and meta-analysis. EurJEpidemiol. 2014;29(11):791-800. doi: 10.1007/s10654-014-9946-8. [PubMed: 25179793].

19. Chen Q, Yan Y, Zhang L, Cheng K, Liu Y, Zhu W. Effect of hyperthyroidism on the hypercoagulable state and thromboembolic events in patients with atrial fibrillation. Cardiology. 2014;127(3):176-82. doi: 10.1159/000356954. [PubMed: 24434544].

20. Yang MH, Yang FY, Lee DD. Thyroid disease as a risk factor for cerebrovascular disease. J Stroke Cerebrovasc Dis. 2015;24(5):912-20. doi: 10.1016/j.jstrokecerebrovasdis.2014.11.032. [PubMed: 25804562]. 